\title{
Sexual desire and orgasmic disorders in female medical students: preliminary results
}

\author{
Fotini Ferenidou*, Nikolaos Vaidakis \\ From $1^{\text {st }}$ International Congress on Neurobiology and Clinical Psychopharmacology and European \\ Psychiatric Association Conference on Treatment Guidance \\ Thessaloniki, Greece. 19-22 November 2009
}

\section{Background}

Female sexual problems are age related, progressive and highly prevalent affecting up to $43 \%$ of women $[1,2]$. Reduced sexual desire disorder and orgasmic disorders are amongst the most frequent female sexual disorders $[1,3]$.

\section{Materials and methods}

The study population included 129 female medical students of the University of Athens, during the academic year 2008-2009. The participants were asked to complete voluntarily and anonymously a self - administered questionnaire which included demographic data and a short questionnaire regarding reduced sexual desire and orgasmic difficulties.

\section{Results}

Mean women's age was 24 years. More than half of them $(58.1 \%)$ were in a stable relationship, while the majority of them $(84.4 \%)$ had sexual activity during the last year. Regarding sexual interest, $66.7 \%$ didn't have any difficulties during the last three months, while nearly one third of the women $(27 \%)$ seem to face some orgasmic difficulties. $39 \%$ of the participants believe that women should reach an orgasm in every sexual intercourse and $30.3 \%$ admit to sometimes pretend reaching an orgasm. Finally, the majority of women are very or quite satisfied with their sexual life $(74.8 \%)$, their emotional closeness with their partner (78\%) and more than half of them (78.2\%) consider sex an important dimension of their total life satisfaction.

\section{Conclusions}

Low sexual desire doesn't seem to be a problem for this group of young women. Orgasmic disorders in this sample are similar to the percentages found by previous studies. Interestingly enough, one third of the participants admit to occasionally faking orgasm to their partner. This group of women presents high levels of sexual satisfaction and emotional bonding, which are important parameters of womens sexuality. Any interpretations of the present study should be made with caution, because our results were based on a small, non-randomized, specific sample.

\section{Published: 22 April 2010}

\section{References}

1. Laumann EO, Paik A, Rosen RC: Sexual dysfunction in the United States: prevalence and predictors. JAMA 1999, 281:537-544.

2. Dunn KM, Croft PR, Hackett Gl: Sexual problems: a study of the prevalence and the need for health care in the general population. Fam Pract 1998, 15:519-524.

3. Rosen RC: Prevalence and risk factors of sexual dysfunction in men and women. Curr Psychiatry Rep 2000, 2:189-195.

doi:10.1186/1744-859X-9-S1-S176

Cite this article as: Ferenidou and Vaidakis: Sexual desire and orgasmic disorders in female medical students: preliminary results. Annals of General Psychiatry 2010 9(Suppl 1):S176. 